\title{
Visual Communication Design of Digital Media in Digital Advertising
}

\author{
Hongni Li* \\ School of Innovation \& Design, Guangzhou Huashang College, Guangzhou 511300, Guangdong Province, China
}

*Corresponding author: Hongni Li, luhei65694@163.com

\begin{abstract}
With the continuous development of modern science and technology, great changes have taken place in the advertising media industry where the traditional form of advertising has gradually changed into digital ones. Compared with the traditional advertising, digital advertising has more flexibility and has a variety of forms in its advertising creation according to product itself. In addition, visual communication design plays a critical role where it is an important way to improve digital advertising. Therefore, it is necessary to optimize visual communication design in order to improve the quality of digital advertising. In this way, this article carries out an in-depth research and analysis on the visual communication design of digital media in digital advertising and put forward some reasonable suggestions and measures, aiming to further promote the development of China's advertising media industry.
\end{abstract}

Keywords: Digital advertising; Digital media; Visual communication; Design scheme; Optimization measure

Publication date: July 2021; Online publication: July 30, 2021

\section{Introduction}

The main function of advertising is to publicize the product through scientific advertising and advertising design which can improve the advertising effect and sales while ensuring authenticity. In digital advertising design, the most important is visual communication design which is the consumers' intuitive impression of advertisements. It mainly includes two basic elements which are visual symbols and transmission. Advertising effect can be improved through scientific design and collocation. The virtual reality technology can be used in digital advertising in which the use of digital media is able to make the contents in advertisements more vivid. This is the key technology to promote the development of the advertising industry. However, in order to improve the quality of digital advertising design, there is a need to optimize visual communication design so that it can meet needs of the people when viewing advertisements.

\section{Introduction to digital advertising and digital media}

Digital media refers to the use of binary digital form of recording, processing, dissemination, and carrier to obtain information. Digital media is regarded as a carrier of advertising, namely digital advertising ${ }^{[1]}$. After years of development, several video websites use digital advertising for publicity which gradually push digital advertising to the peak of its' development. At present, it has become the mainstream form of advertising. With the combination of digital technology and advertising technology to promote the continuous development of the advertising industry, the current digital advertising has developed into the procedural stage. A large number of digital media resources and digital technologies can be made use to innovate and develop advertising contents and their forms of expressions which would be the focus of the future development in the advertising marketing industry. 


\section{Analyzing the visual communication design characteristics of digital media in digital advertising}

\subsection{Guiding characteristics}

Visual communication design focuses on guidance. Advertising design is carried out from the perspective of guidance where the guidance design will be completed according to people's visual process. Visual process refers to the basic process where people obtain information through vision. However, there are some limitations whereby people cannot perceive all the information in the external environment at the same time, so they need to perceive external information through movement. Digital media in digital advertising is a concept of movement which includes a number of core technologies such as flash animation technology, three-dimensional virtual reality technology, etc. Some information in digital advertisement can be developed or emphasized by adopting corresponding technologies which makes people pay more attention to a certain content in the advertisement and their vision would remain fixed on that guiding content. This kind of advertisements would create visual stimulation effect and arouse people's excitement when watching them which is the main feature of digital advertisements ${ }^{[2]}$.

\subsection{Interactive features}

Digital media has good interactivity, and hence digital advertising with digital media as the carrier also has good interactivity. In digital advertising design, there is a need to consider the basic characteristics and laws of technology while taking into account the psychological development characteristics of consumers in order to determine the interaction points between digital advertising and consumers for improving the interactivity of digital advertising. In the era of digital media, the visual communication design of digital advertising needs to be integrated with the media to build an integrated mode. For example, the basic information of advertising can be integrated with digital technology with the help of animation technology, so as to form an interactive digital advertisement with real-time questions and answers. Users would be able to enter the next level of advertising interface by clicking on a button in the advertisement and obtain different information in the advertisement at the same time which makes a more comprehensive presentation effect of the advertising information. This is an important way to improve the effect of advertising.

\subsection{Humanized features}

The ultimate goal of advertising is to publicize the content while the ultimate goal of publicity is to help people to clearly understand the product content in order to generate the desire to purchase, so the consumers are the ultimate service subjects. Therefore, advertising must have the characteristics of humanization. In the current digital advertising, humanization is always taken as the core feature. Digital advertising designs are closer to the characteristics of consumers' psychological activities and the direction of psychological development, visual process and cognitive law, etc., so that people would be able to accept the information and contents in advertisements as well as improve the depth of advertising in consumers' psychological cognition. This improves the publicity effect of advertising, promotes the sales of products, and realize the final design of digital advertising. Hence, there is a need to strengthen humanized designs.

\section{Analyzing the visual communication design of digital advertisement}

Digital advertising is mainly based on website advertising. It is able to make the advertising content richer through the use of website-related technologies. Especially in terms of visual communication effect, it can comprehensively improve the visual communication effect and enhance the visual expression of advertising, so as to improve the publicity effect of digital advertising. Therefore, it is necessary to strengthen the visual 
communication design of digital advertising and improve the effect of digital advertisement designs with scientific technology and scheme.

\subsection{Three-dimensional design}

Three-dimensional design which is different from the traditional two-dimensional graphic design is an important aspect in visual communication design of digital advertising. The advertising information can be more three-dimensional and dynamic through the use of three-dimensional design. This makes the visual communication effect more vivid and have stronger impacts. For example, virtual reality technology is used for three-dimensional design in the visual communication effect of digital advertising so that the product can be presented in the three-dimensional form. This improves the information expression ability of digital advertising and consumers can then understand the basic micro information of the product from a full perspective. At the same time, combined with certain artistic designs, the artistry and beauty of visual communication in digital advertising can be improved which makes the consumers more acceptable to the information contents. Three-dimensional design is the most basic and applied design method in the visual communication design of current digital advertising. As traditional advertising is embodied in the twodimensional form, three-dimensional visual effect can bring direct and stronger visual impact. This makes the consumers easier to accept from the visual aspect. At the same time, the three-dimensional design is an effective way to improve the effect and visual impact of digital advertising in which consumers would have more profound impressions ${ }^{[3]}$.

\subsection{Visual impact design}

Visual impact design is also an important way to improve the publicity effect of digital advertising. It does not only include the three-dimensional design technology mentioned above but it also uses a variety of other modern information technologies to achieve the three-dimensional design of a product in the digital advertising content. On the basis of color matching, animation design, sound effect design, etc., the visual impact of digital advertising is better. In this way, it can improve the attractiveness of advertising so that consumers can be unconsciously attracted by the advertising contents. There are many ways to improve the visual impact of digital advertising, mainly by using computer technology to magnify the details of a product. Using the visual impact design of digital advertising in regard to automobile products as an example, it is mainly through the accumulation of information technology that a 1:1 model of a completely restored automobile is established and all the price details are displayed in the model in order to benefit the consumers to have a more intuitive and comprehensive immersive visual effect experience. This can improve the impact of digital advertising visual communication; thus, it is an effective way to improve the visual communication effect.

\subsection{Visual acceptance and psychological acceptance}

Consumers are always the ultimate service subjects of digital advertising. Hence, there is a need to pursue the visual and psychological acceptance of consumers. There are various design schemes to improve the visual impact of digital advertising. However, there is a need to consider that the audiences are in accord to their own psychological acceptance ability, or it would be counterproductive to use exaggeration or other ways to improve the visual impact which might cause consumers to have repulsive emotions or a difficulty to accept it. Visual communication design is an important way to improve the effect of digital advertising; hence, the visual acceptance and psychological acceptance of the targeted audiences have to be considered. With scientific design scheme and on the basis of ensuring the authenticity of a product information, artistic processing method, virtual reality combination, and other methods can be adopted to improve the visual 
communication expressive impact of advertising information and at the same time, portray good aesthetic and artistry features. Only in this way can the visual communication design effect be improved and by using technical advantages, the expressive impact of digital advertising can be enhanced.

\section{Conclusion}

To sum up, this article expounds the basic connotation of digital advertising, analyzes the basic characteristics of digital advertising, and finally put forward a number of ways to improve the visual communication design effect of digital advertising in hope to provide some suggestions and help for the advertising design industry in China as well as to constantly promote the quality of China's digital advertising design.

\section{Funding}

Research on the Business Model of Mobile Short Video and a Joint Project in the "13th Five-Year Plan" for the Development of Philosophy and Social Sciences in Guangzhou (Number: 2020GZGJ211).

\section{Disclosure statement}

The author declares that there is no conflict of interest.

\section{References}

[1] $\mathrm{Lu} \mathrm{W,} \mathrm{2020,} \mathrm{On} \mathrm{the} \mathrm{Embodiment} \mathrm{and} \mathrm{Application} \mathrm{of} \mathrm{Digital} \mathrm{Media} \mathrm{Technology} \mathrm{in} \mathrm{Visual}$ Communication Design. Satellite TV and Broadband Multimedia, 508(003): 200-1.

[2] Cai H, Cai S, 2019, Embodiment and Application of Digital Media Technology in Visual Communication Design. Masterpieces, 000(004): 102.

[3] Nie M, 2019, Application Analysis of Dynamic Visual Communication Design in Digital Media. Artist, 000(010): 39 . 